\title{
In planta selection of plant growth promoting endophytic bacteria for rice (Oryza sativa L.)
}

\author{
H. Etesami, $\mathrm{H}^{1 *}$, Mirseyed Hosseini ${ }^{1}$, H.A. Alikhani ${ }^{1}$, \\ ${ }^{1}$ Department of Soil Science, College of Agriculture \& Natural Resources, University of Tehran, Karaj, Iran. *Corresponding \\ author: hassanetesami@ut.ac.ir
}

\begin{abstract}
In this study, bacteria were isolated from the rhizosphere and inside the roots of canola (Brassica napus L.) plants grown in the field from northern Iran. Firstly, 150 strains (endophytic and rhizospheric isolates) isolated from canola were characterized for plant growth promoting (PGP) traits. Of them, one hundred isolates produced indole3 -acetic acid (IAA), whereas 17 isolates solubilized phosphate, 44 isolates produced siderophore, 34 produced 1-aminocyclopropane-1-carboxylate (ACC) deaminase and five produced hydrocyanic acid (HCN). All of the screened isolates with different growth promoting traits were separately inoculated as different mixtures on two rice cultivars under gnotobiotic conditions. A total of 22 endophytic isolates were re-isolated from two rice cultivars and characterized for Plant Growth Promoting (PGP) traits again. All 22 endophytic isolates produced IAA. Secondly, the colonization and growth promoting effects of the IAA producing endophytic strains were compared in inoculated rice plantlets as single-strain inoculants. All of the IAA producing strains were consistently more active in colonizing rice seedlings as compared with other isolates. Therefore, it seems that IAA production may be required for endophytic competence as compared to other PGP traits in rice seedlings. In addition, this study indicates that the selected bacterial isolates based on their IAA producing trait have the potential for PGP and more colonization of rice.
\end{abstract}

Keywords: Root colonization, endophyte, canola, rice, plant growth promoting traits, IAA

\section{Introduction}

Endophytic bacteria can be defined as those bacteria that can colonize the internal tissue of the plant without imposing negative effects on their host (Ryan et al., 2008). Endophytes promote the growth of plants in various ways similar to rhizosphere bacteria. For example they can enhance plant growth by phosphate solubilization, production of siderophore, indole3 -acetic acid (IAA) and 1-aminocyclopropane-1- carboxylate (ACC) deaminase, biological nitrogen fixation, etc. (Kevin, 2003; Bhattacharyya and Jha, 2012). During the last few years, there has been an increased interest in exploring the possibility of extending the beneficial interactions between rice and some of plant growth promoting (PGP) bacteria including $\mathrm{N}_{2}$-fixing bacteria. Many reports strongly suggest that endophytes have an excellent potential to 
be used as plant growth promoters with legumes and non-legumes (Antoun et al., 1998). Yanni et al. (1997) showed that rhizobia can naturally colonize inside rice roots rotated with berseem clover and assessed the potential effect of this novel plant-microbe association on rice yield. In Iran, the second cropping in rotation with rice is berseem clover and canola. We were also interested in assessing the possible existence and agronomic importance of naturally occurring endophytes within rice roots, in Iran where rice is in rotation with canola. PGP traits can be estimated under In vitro conditions and allow the selection of isolates that could lead to increased plant growth (Yanni et al., 1997). The use of beneficial bacteria as agricultural inputs for increasing crop production needs the selection of competent rhizobacteria with PGP traits. Nature selects endophytes that are competitively fit to inhabit compatible niches within this nutritionally enriched and protected habitat of the root interior without causing pathological stress on the host plant. However, when screening these bacteria for other PGP agents, it is better to be screened these bacteria for achieving the most promising isolates having suitable colonization and PGP attributes. In most research, it has been seen that following incubation, bacterial flora are taken at random from plates or morphological representatives are selected for further study. However, this type of selection may remove some superior bacteria in terms of PGP traits and with high colonization ability. Therefore, it is essential to study all isolated bacteria in an economic way and select the best bacteria in terms of PGP traits and high colonization rate. On the other side, if we screen all strains for all PGP traits, the process will take a long time and will be costly. Since the ability to colonize roots is a necessary condition for a rhizobacteria to be considered as a true PGPR (Silva et al., 2003), we would not need to identify the PGP traits of all of the isolates, just those that are able to establish themselves in rice roots. Therefore, we were interested in finding an important auxiliary tool for helping in selection of the isolates with colonization and plant growth promoting rhizobacteria (PGPR) potentiality. Yanni et al. (1997) showed that in spite of developing higher populations within roots of Indica rice, endophytic bacteria elicited higher short-term PGP responses on the Japonica rice. They indicated that identification of superior combinations of rhizobia and rice genotypes for optimal growth responses would likely require PGP bioassays rather than just an assessment of the bacterial endophyte's ability to colonize the root interior. Several molecular methods have been used to exhibit that root colonization is taking place (Silva et al., 2003). However, these methods are relatively expensive and time-consuming. Hence, the objective of this study was to find the most PGP trait in endophytic bacteria isolated from canola of more colonization and enhanced growth of rice seedlings. The results may be used to screen the strains that will be effective in colonizing rice plant and consequently plant growth after inoculating them to plant.

\section{Materials and Methods}

\subsection{Isolation of endophytic and rhizosphere bacteria and growth conditions}

Endophytic and rhizosphere bacteria were isolated from roots and rhizosphere soil of the canola (Brassica napus L.) plants collected, at flowering, from Dashte Naz Research Farm, Māzandarān, Iran respectively. The plant roots were surface sterilized for $30 \mathrm{~s}$ with $95 \%$ ethanol solution and subsequently with $2 \%$ sodium hypochlorite containing $0.1 \%$ Tween 20 (Sigma-Aldrich Co., St. Louis, Mo.). To remove the disinfectant, the roots were rinsed five times in two washes of nonsterile deionized distilled water and a wash of sterile water; the roots were dried with sterile paper towels. To confirm surface-sterilization, root pieces were pressed onto, and aliquots of water from the final rinse solutions were plated on tryptic soy agar (TSA, Difco, NJ, USA) plates and tested for contaminants. No contaminants were found indicating that the surface-sterilization procedure was effective. The root tissue was triturated by sterile porcelain mortar with sterile $12.5 \mathrm{mM}$ potassium phosphate buffer $(\mathrm{pH}$ 
7.1). The tissue extracts were then serially diluted in phosphate buffer and plated in triplicate on TSA plates to recover any bacterial endophytes present in the plant tissue. For isolating rhizosphere bacteria, soil adhered to roots were collected. After proper mixing, $10 \mathrm{~g}$ soil was transferred to a $250 \mathrm{ml}$ Erlenmeyer flask containing $90 \mathrm{ml}$ sterile distilled water and shaken (at $120 \mathrm{rpm}$ ) for $30 \mathrm{~min}$. Dilution series (up to $10^{-8}$ ) were made and $0.1 \mathrm{ml}$ aliquots were spread on TSA plates. All the plates were incubated at $28{ }^{\circ} \mathrm{C}$ for $3-5$ days at which time the number of colony-forming units (CFU) were counted. Numbers of bacterial cells recovered were expressed as CFU g ${ }^{-1}$ fresh tissue weight and soil for endophytic and rhizosphere bacteria respectively. The bacterial colonies were initially screened and grouped by colony color and morphological characteristics. The purified colonies were stored in a refrigerator at $4{ }^{\circ} \mathrm{C}$ for further studies and ower case letter long term storage at $-20{ }^{\circ} \mathrm{C}$, the isolates were preserved in the glycerol stocks $(20 \%)$.

\subsection{In vitro screening of bacterial isolates for their $P G P$ activities}

\subsubsection{Siderophore production}

Production of siderophore was determined as described by Schwyn and Neilands (1987). Briefly, the isolates were spotted on chrome azurol S (CAS) agar media and incubated at $28 \pm 2{ }^{\circ} \mathrm{C}$ for 2 days. The presence of orange halos around the colonies was considered as indicator for the presence of siderophores. Siderophore production index was evaluated according to the ratio of the halo diameter (HD) to the colony diameter (CD).

\subsubsection{IAA production}

It was determined as described by Patten and Glick (2002). The isolates were grown in $100 \mathrm{ml}$ flasks containing $50 \mathrm{ml}$ Luria broth (LB) supplemented with L-tryptophan $\left(100 \mu \mathrm{g} \mathrm{ml}^{-1}\right)$ for $48 \mathrm{~h}$ on a rotary shaker. Then, cultures were centrifuged at $10,000 \mathrm{~g}$ for $15 \mathrm{~min}$ and the supernatants collected. Two $\mathrm{ml}$ of Salkowsky reagent $\left(1 \mathrm{ml}\right.$ of $0.5 \mathrm{M} \mathrm{FeCl}_{3}$ in $50 \mathrm{ml}$ of $35 \% \mathrm{HClO}_{4}$ ) with One $\mathrm{ml}$ of the supernatant was allowed to react with at $28 \pm 2{ }^{\circ} \mathrm{C}$ for $30 \mathrm{~min}$. Pink color developed indicating the presence of IAA was determied by measuring the absorbance in a spectrophotometer at $535 \mathrm{~nm}$ at the end of the incubation. A standard curve was plotted with IAA and Salkowsky reagent dissolved in LB medium to quantify the IAA ( $\mu \mathrm{g} \mathrm{ml}^{-1}$ ) present in the culture filtrate.

\subsubsection{Phosphate solubilization}

Ability of phosphate-solubilizing of the bacteria was determined on Pikovskaya agar (1948). The isolates were spotted onto Pikovskaya agar and incubated for 3 days at $28 \pm 2{ }^{\circ} \mathrm{C}$. The presence of halo zone around the bacterial colony was considered as indicator for positive mineral phosphate solubilization. Solubilization index was evaluated according to the ratio of the halo diameter (HD) to the colony diameter (CD).

\subsubsection{ACC-deaminase production}

The ability of the isolates to utilize ACC was assayed based on their ability to use ACC as a sole nitrogen source (Penrose and Glick, 2003). Briefly, the isolates were cultured first in rich medium (TSB) and incubated at $28^{\circ} \mathrm{C}$ at $120 \mathrm{rpm}$ for $24 \mathrm{~h}$. The cells were harvested by centrifugation at $3000 \mathrm{~g}$ for $5 \mathrm{~min}$ and washed twice with sterile $0.1 \mathrm{M}$ Tris- $\mathrm{HCl}(\mathrm{pH} 7.5)$ and resuspended in $1 \mathrm{ml}$ of $0.1 \mathrm{M}$ Tris- $\mathrm{HCl}(\mathrm{pH} 7.5)$ and spot inoculated on plates containing Dworkin-Foster's salt minimal medium (without nitrogen source) containing $3.0 \mathrm{mM}$ ACC or $0.1 \mathrm{M}\left(\mathrm{NH}_{4}\right)_{2} \mathrm{SO}_{4}$ as a $\mathrm{N}$ source. The $3 \mathrm{mM}$ ACC were filter sterilized with $0.2 \mu \mathrm{m}$ membrane filter and was stored at $-20{ }^{\circ} \mathrm{C}$ before the assay. Prior to inoculation, the ACC solution was thawn and properly added to sterile DF medium. Following inoculation with the isolates, the cultures were incubated at $28 \pm 2$ ${ }^{\circ} \mathrm{C}$ for three days. The ability of the isolates to utilize ACC was confirmed by inoculating the isolates in negative control plates containing DF medium without any $\mathrm{N}$ source and positive control plates containing only DF medium with $0.1 \mathrm{M}\left(\mathrm{NH}_{4}\right)_{2} \mathrm{SO}_{4}$. The absence of growth approved the utilization of ACC as N source. 
Growth of isolates, colony diameter (CD, in $\mathrm{mm}$ ), on ACC supplemented plates was compared to negative and positive controls and was considered as an index for evaluating ACC deaminase producing isolates.

\subsubsection{HCN production}

Production of $\mathrm{HCN}$ was estimated qualitatively according to the methodology described by Lorck (1948). The isolates were grown in LB agar supplemented with glycine $\left(4.4 \mathrm{~g} \mathrm{~L}^{-1}\right)$. One sheet of the sterilized whatman filter paper was immersed in $1 \%$ picric acid in $10 \%$ sodium carbonate for $1 \mathrm{~min}$ and struck underneath the Petri dish lids. The plates were sealed with parafilm and incubated at $28 \pm 2^{\circ} \mathrm{C}$ for 2 days. Development of reddish brown color on the Whatman filter paper indicated production of $\mathrm{HCN}$.

\subsection{Colonization assay}

For this study, we used two rice (Oryza sativa L.) cultivars: Khazar (a bred cultivar) and Hashemi (a non bred cultivar) obtained from the Rice Research Institute in Iran. Both cultivars have currently been introduced and cultivated in Māzandarān provience in rotation with canola. Before assaying colonization to find competent endophytes, we established separate tests that seeds of these two rice cultivars harbored no endophytic bacteria. For colonization assay, we used the method described by Yanni et al. (1997) with some modification. Surface-sterilized seeds were grown in tubes including Hoagland's plant growth medium in absence or presence of $8 \mathrm{mM}\left(\mathrm{NH}_{4}\right)_{2} \mathrm{SO}_{4}$. Tubes were incubated for 3 days in the dark at $30{ }^{\circ} \mathrm{C}$ for seed germination. Before inoculating rice seedlings with bacterial isolates, it was essential to determine whether there was any antagonistic effect between the isolates, since all isolates as batch inoculations were inoculated onto rice seedlings. To find isolates without any antagonistic effect with each other, we did In vitro antagonistic assay on all isolates as described by Etesami et al. (2014). For preparing the bacterial cultures, each bacterial isolate was grown in 250-ml flasks containing $100 \mathrm{ml} \mathrm{NB}$ medium and incubated for
$24 \mathrm{~h}$ at $28^{\circ} \mathrm{C}$. After incubation, the cell suspension was centrifuged at $5,000 \times \mathrm{g}$ for $10 \mathrm{~min}$ and the pellet was resuspended in $0.85 \%$ sterilized saline solution. The bacterial culture was standardized to $5 \times 10^{8} \mathrm{CFU} \mathrm{ml}^{-1}$. One hundred IAA producing isolates were inoculated as five mixtures of 20 strains each on two rice cultivars, whereas siderophore and ACC deaminase producing isolates were inoculated as two mixtures of 22 strains each and two mixtures of 17 strains each on two rice cultivars respectively. Phosphate solubilizing isolates and $\mathrm{HCN}$ producing isolates were also inoculated on two rice cultivars all together. Each seedling root was inoculated with $100 \mu \mathrm{l}$ of bacterial inoculum of each isolate grown separately on NB medium and incubated in a growth chamber. Rice seedlings in tube culture were gently uprooted 20 days after inoculation, and then excised at the stem base. Endophytic strains were isolated from roots of rice seedlings as described above. The endophytic isolates recovered from two rice cultivars were characterized for PGP traits once again.

\subsection{Examinations of rice growth responses after inoculation with IAA producing isolates}

Endophytic colonization of rice roots (Khazar cultivar) only by seven IAA producing isolates reisolated from Khazar and assessment of their potential to promote plant growth were carried out. This assay was performed , using the same procedures as described above, but in this assay, the bacterial inocula were suspended in sterile Hoagland's medium containing $8 \mathrm{mM}\left(\mathrm{NH}_{4}\right)_{2} \mathrm{SO}_{4}$ as single-strain inoculants. Shoot biomass (stem plus leaves), root mass were measured as dry and fresh weights, respectively. In addition, root length was measured. Reisolation and viable plate counting of endophytic isolates populations were also carried out as described above.

\subsection{Statistical analysis}

All the experiments were arranged in randomized complete design with four replications in each treatment and repeated twice. Analysis of variance (ANOVA) was performed and means were compared by the Tukey test 
at $5 \%$ probability level using the SAS (V. 8) software package (SAS Institute, Cary, NC, USA).

\section{Results}

\subsection{Isolation of bacteria}

A total of 150 bacterial isolates were isolated from the rhizosphere (90 isolates) and surface-sterilized roots (60 isolates) of canola grown in rotation with rice in the Dashte Naz region of Mazandaran, in Iran. Colony and cell morphology and gram-staining tests were performed on the isolates. No further attempts for identification were made. The population sizes of endophytic and rhizosphere isolates varied from $10^{4}$ to $10^{7} \mathrm{CFU} \mathrm{g}^{-1}$ fresh tissue weight. Preliminary characterization of these bacteria showed that approximately equal percentages of gram-positive and gram-negative bacteria were isolated from the plants. All isolates were used for detailed investigation.

\subsection{Plant growth-promoting traits of isolates}

All endophytic and rhizosphere isolates were characterized for PGP traits. When the bacterial isolates were evaluated for their plant growth-promoting traits, one hundred isolates produced IAA, 44, five and 34 produced siderophore, HCN and ACC deaminase respectively, whereas 17 isolates solubilized phosphate. The 100 isolates produced IAA between $1.21 \pm 0.16$ to $24.12 \pm 0.23 \mu \mathrm{g} \mathrm{ml}^{-1}$. Occurrence of various plant growth promoting features among different isolates is shown in Figure 1.

\subsection{Colonization of rice seedlings by isolated strains from canola}

To determine which of the endophytic bacteria had the ability to colonize and persist at high levels in two rice cultivars, we carried out studies with a controlled system, using axenic rice plantlets. In all colonization studies, controls were included to verify that the inoculated bacteria were recovered. No bacteria could be isolated from non-inoculated plants. All 150 isolates were inoculated as mixtures of strains as mentioned above into the rice hosts and grown under gnotobiotic conditions. The influence of nitrogen fertilization in the experiments conducted with bacterial strains was performed with axenic plantlets cultured on Hoagland's growth media supplemented with and without $8 \mathrm{mM}\left(\mathrm{NH}_{4}\right)_{2} \mathrm{SO}_{4}$. Colonization extent was higher (22-25 isolates) in roots in presence of $\mathrm{N}$; compared with roots in absence of $\mathrm{N}$ (19-22 isolates) (Table 1). Plantlets cultivated for 20 days in the presence of $\left(\mathrm{NH}_{4}\right)_{2} \mathrm{SO}_{4}$ showed an increase in bacterial invasion levels as compared to plantlet cultivated in the absence of $\left(\mathrm{NH}_{4}\right)_{2} \mathrm{SO}_{4}$. Plating experiments of macerates from surface-sterilized roots of the inoculated plants indicated substantial populations of the endophytic bacteria, the magnitude of which varied with the rice cultivar, and the plant growth medium (Table 1). For example, out of 100 IAA producing isolates inoculated on Khazar cultivar, seven endophytic strains had colonized the plants at levels ranging from 6.8 to $7.3 \log 10 \mathrm{CFU} \mathrm{g}^{-1}$ ( root fresh weight) at 20 days post inoculation (Table 1), whereas of 44 siderophore, 34 ACC deaminase and five $\mathrm{HCN}$ producing isolates inoculated, five, four, three endophytic isolates had colonized the plants respectively. In addition, three phosphate solubilizing isolates were recovered from rice seedlings. Although the number of recovered isolates (41 isolates vs. 47 isolates) and the highest proportions of endophytes that were able to colonize the rice seedlings were obtained from Hashemi cultivar, the endophytic bacterial population was not significantly affected ( $p<$ $0.05)$ by the plant growth medium ( $\mathrm{N}$-fertilization), rice cultivar and by isolates with different PGP traits. Size of colonization of the isolates varied from $10^{4}$ to $10^{7} \mathrm{CFU} \mathrm{g}^{-1}$ root fresh weight (Table 1). The results show that the $\mathrm{N}$-fertilization did not affect the bacterial endophytic population on rice seedlings. The highest proportions of endophytes that were able to colonize the hosts were obtained from Hashemi cultivar grown in Hoagland $+\mathrm{N}$ growth medium (Table 1), however, this difference was not 
significant. The results also indicated no signs of

pathogenicity, such as lesion formation or wilting in the seedlings incubated with bacterial cultures.

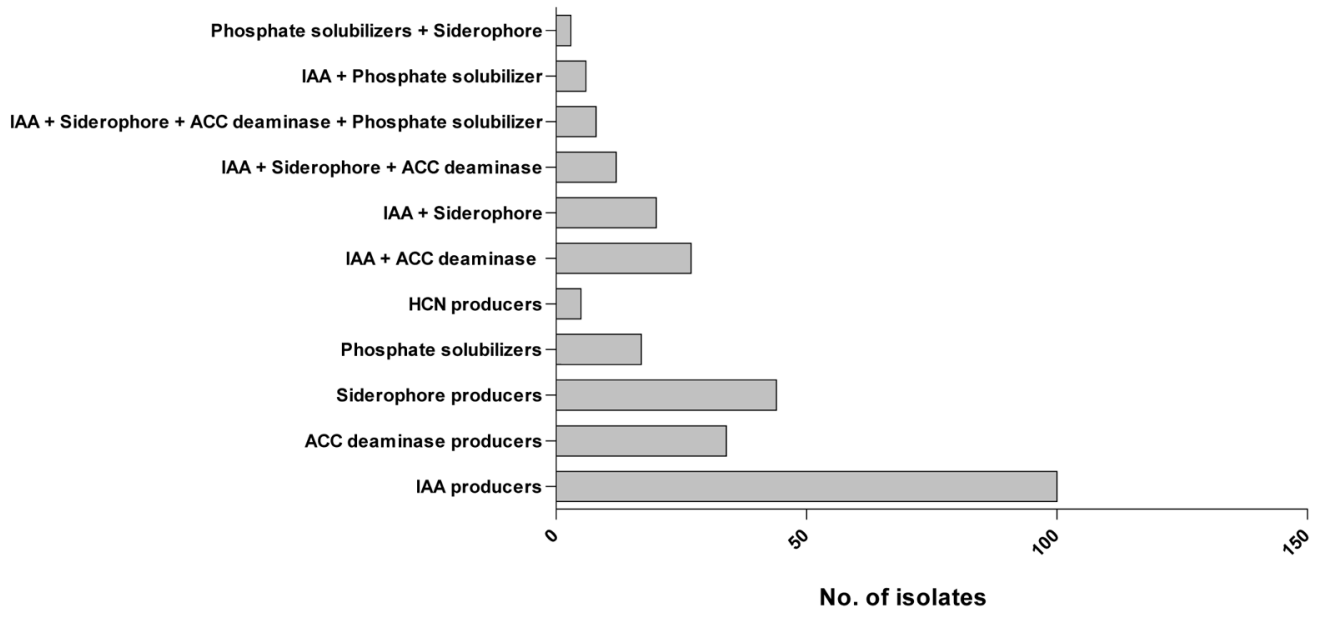

Figure 1. Occurrence of different PGP traits among 60 endophytic isolates and 90 rhizosphere isolates. These isolates were screened for individual PGP characters and combination of PGP characters. All isolates were grown under identical conditions for testing PGP characters. Results are based on two experiments conducted separately but under identical conditions

\subsection{Plant growth-promoting traits of recovered isolates from rice seedlings}

We recovered 22 and 19 isolates of Khazar cultivar grown in the growth medium with and without $\mathrm{N}$ source respectively. In addition, 25 and 22 isolates were also reisolated from Hashemi cultivar in the growth medium with and without $\mathrm{N}$ source respectively (Table 1). To re-screen the recovered isolates from rice seedlings for PGP traits, we studied only 22 recovered isolates from Khazar cultivar in growth medium including $\mathrm{N}$ source. This was due to the fact that, identifying the applied isolates was not possible and in addition, the number of reisolated strains were closely the same. All 22 strains recovered from inside rice roots were characterized for PGP traits. When the bacterial isolates were evaluated for their PGP traits, all isolates produced IAA, whereas the production ability of other PGP traits was not observed among all of the isolates (Table 2). The 22 isolates produced IAA between 10 and $24 \mu \mathrm{g} \mathrm{m}{ }^{-1}$. In addition, the amount of production of PGP traits in the re-isolated strains from two rice cultivars were more than that of other isolates which were not able to inoculate inside rice seedlings (data not shown).

\subsection{Rice seedlings growth responses}

Efficient establishment of endophytic colonization of rice plants by seven IAA producing endophytes was demonstrated with a gnotobiotic system, using axenic rice plantlets. Bacterial strains were successfully reisolated from roots of rice seedlings and a considerably high recovery was recorded from rice plants of 20 days after inoculation. 
Table 1. Bacterial endophyte recovery from two rice cultivars and CFU counts of the endophytic bacteria colonizing internal part of rice roots in gnotobiotic tube culture in Hoagland liquid with $(+\mathrm{N})$ and without $(-\mathrm{N})$ nitrogen $(8$ $\mathrm{mM}$ as $\left.\left(\mathrm{NH}_{4}\right)_{2} \mathrm{SO}_{4}\right)$ after inoculation with different mixtures of the rhizosphere and endophytic strains isolated from canola having different PGP traits for 20 days

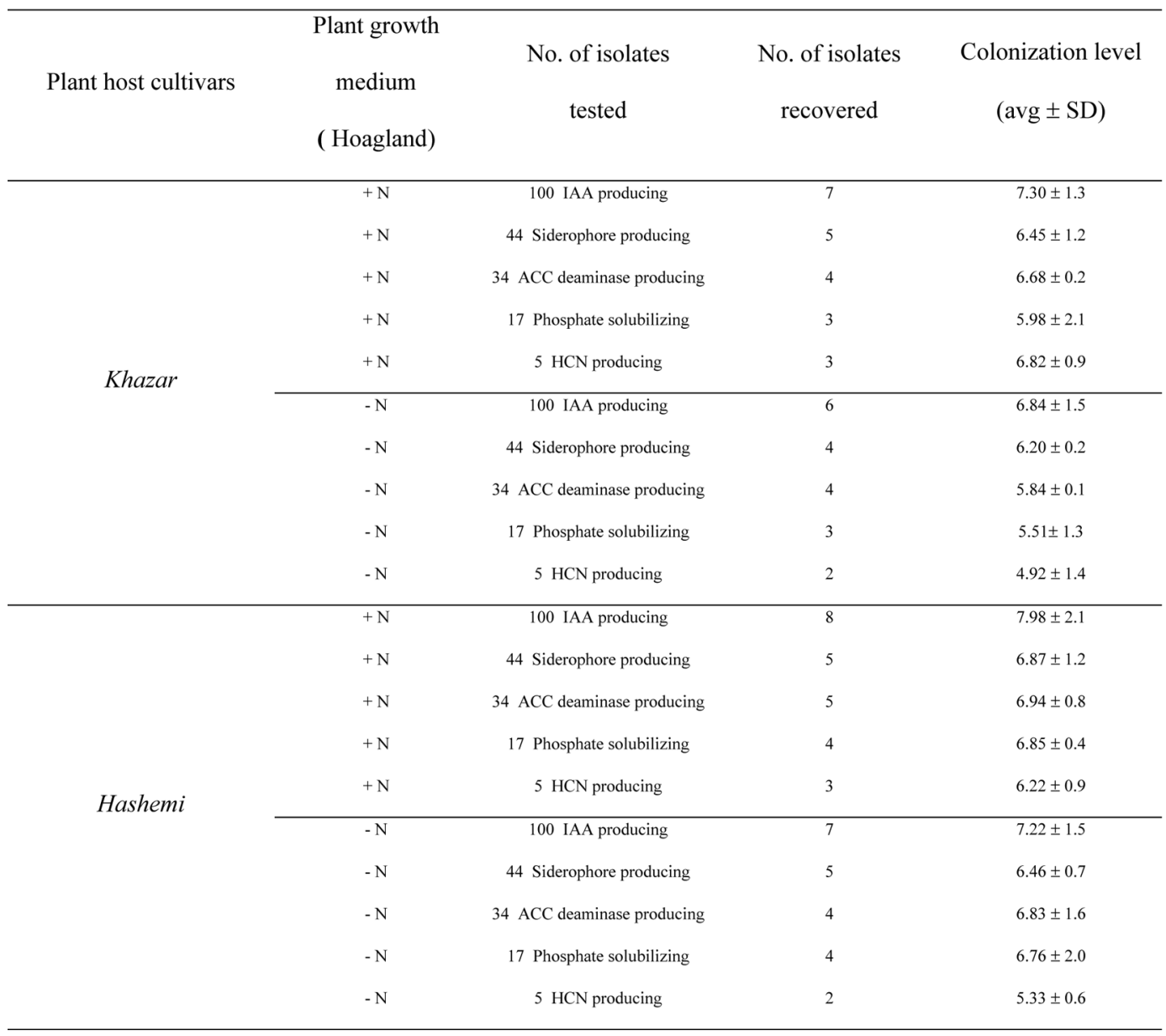

The average number of strains endophytically colonizing roots of Khazar cultivar was $6.3 \times 10^{5} \mathrm{CFU}$ $\mathrm{g}^{-1}$ fresh weight plantlet tissue. The colonization levels of these isolates were also significant (Table 3). The Inoculated roots appeared healthy without development of nodule-like hypertrophies or obvious symptoms of disease. Under these experimental conditions, internal root colonization by the isolates was not suppressed in Hoagland's No. 2 plant growth medium, which contains $\mathrm{NH}_{4}^{+}$as source of $\mathrm{N}$. Colonization by the strains induced a large increase in root hair number and length in all inoculated plants (Figure 2). The presence of a higher number of lateral roots and more abundant root hairs were observed in response to colonization by the strains when compared with noninoculated plants. 
All of the IAA producing isolates increased shoot dry mass by $5.7-27.5 \%$, root fresh mass by 2.9 $41 \%$ and root length by $8-54 \%$, over the control. The isolate I4 demonstrated to be the best plant growth promoting endophyte, with an increase of root fresh weight and $27 \%$ in shoot dry weight as compared with control (Table 3). A significant relationship among IAA producing isolates, rate of root colonization and plant growth was observed (Figure 3).

Table 2. Plant growth promoting activities of 22 canola endophytic strains re-isolated from the root interior of rice (Khazar vareity) grown in gnotobiotic tube culture in Hoagland liquid with nitrogen $\left(8 \mathrm{mM}\right.$ as $\left.\left(\mathrm{NH}_{4}\right)_{2} \mathrm{SO}_{4}\right)$ for 20 days.

\begin{tabular}{|c|c|c|c|c|c|}
\hline Isolates $^{a}$ & $\begin{array}{l}\text { Siderophore } \\
\text { production }\end{array}$ & $\begin{array}{l}\text { Phosphate } \\
\text { solubilization }\end{array}$ & $\begin{array}{l}\text { IAA production } \\
\left(\mu \mathrm{g} \mathrm{ml}^{-1}\right)\end{array}$ & $\begin{array}{c}\mathrm{HCN} \\
\text { production }\end{array}$ & $\begin{array}{c}\text { ACC } \\
\text { deaminase } \\
\text { activity }\end{array}$ \\
\hline I1 & - & - & + & - & + \\
\hline I2 & + & - & + & - & - \\
\hline I3 & + & - & + & + & - \\
\hline I4 & + & - & + & - & + \\
\hline I5 & - & + & + & - & + \\
\hline I6 & - & + & + & - & - \\
\hline I7 & + & - & + & - & + \\
\hline S1 & + & - & + & - & - \\
\hline S2 & + & + & + & - & - \\
\hline S3 & + & - & + & - & + \\
\hline S4 & + & - & + & - & - \\
\hline S5 & + & - & + & - & - \\
\hline $\mathrm{A} 1$ & + & - & + & - & + \\
\hline A2 & - & + & + & + & + \\
\hline $\mathrm{A} 3$ & - & - & + & - & + \\
\hline A4 & + & - & + & - & + \\
\hline P1 & + & + & + & - & - \\
\hline P2 & - & + & + & - & - \\
\hline P3 & - & + & + & - & + \\
\hline $\mathrm{Hl}$ & + & - & + & + & - \\
\hline $\mathrm{H} 2$ & - & + & + & - & + \\
\hline H3 & - & - & + & + & - \\
\hline
\end{tabular}

The presence of an activity is indicated by "+" and the absence is indicated by "."”. a: I,S,A,H and P stand for IAA, siderophore, ACC deaminase, $\mathrm{HCN}$ producing isolates and phosphate solubilizing isolates respectively 
Table 3. Evaluation of various morphological responses of rice (Khazar cultivar) and CFU counts of endophytic bacteria colonizing internal part of roots in gnotobiotic tube culture for 20 days in Hoagland liquid with nitrogen $\left(8 \mathrm{mM}\right.$ as $\left.\left(\mathrm{NH}_{4}\right)_{2} \mathrm{SO}_{4}\right)$ after inoculation with seven IAA producing endophytes.

\begin{tabular}{|c|c|c|c|c|c|}
\hline Isolates & IAA production $\left(\mu \mathrm{g} \mathrm{ml}^{-1}\right)$ & Colonization level $(\mathrm{Avg} \pm \mathrm{SE})$ & Root length (cm) & Root fresh weight (mg/tube) & Shoot dry weight (mg/tube) \\
\hline I4 & $18.84 \pm 0.59 \mathrm{a}$ & $6.67 \pm 0.42 \mathrm{a}$ & $4.42 \pm 0.13 \mathrm{a}$ & $1.43 \pm 0.12 \mathrm{a}$ & $25.32 \pm 0.22 \mathrm{a}$ \\
\hline I7 & $17.79 \pm 0.49 \mathrm{ab}$ & $6.11 \pm 0.36 \mathrm{~b}$ & $3.89 \pm 0.2 \mathrm{~b}$ & $1.34 \pm 0.18 b$ & $24.4 \pm 0.16 \mathrm{~b}$ \\
\hline $\mathrm{I} 3$ & $16.52 \pm 0.62 \mathrm{~b}$ & $5.71 \pm 0.32 \mathrm{c}$ & $3.47 \pm 0.11 \mathrm{c}$ & $1.31 \pm 0.57 \mathrm{c}$ & $23.5 \pm 0.14 \mathrm{c}$ \\
\hline Il & $14.54 \pm 0.30 \mathrm{c}$ & $5.14 \pm 0.28 \mathrm{~d}$ & $3.24 \pm 0.3 \mathrm{~cd}$ & $1.24 \pm 0.18 \mathrm{~d}$ & $22.57 \pm 0.11 \mathrm{~d}$ \\
\hline I5 & $13.02 \pm 0.27 \mathrm{~cd}$ & $4.84 \pm 0.38 \mathrm{~d}$ & $3.2 \pm 0.16 \mathrm{~cd}$ & $1.16 \pm 0.17 \mathrm{e}$ & $22.05 \pm 0.12 \mathrm{e}$ \\
\hline I6 & $12.42 \pm 0.31 \mathrm{~d}$ & $4.43 \pm 0.47 \mathrm{e}$ & $3.15 \pm 0.4 \mathrm{~d}$ & $1.07 \pm 0.34 \mathrm{f}$ & $21.42 \pm 0.04 \mathrm{f}$ \\
\hline I2 & $11.71 \pm 0.40 \mathrm{~d}$ & $4.11 \pm 0.31 \mathrm{f}$ & $3.1 \pm 0.12 \mathrm{de}$ & $1.05 \pm 0.13 \mathrm{fg}$ & $21 \pm 0.17 \mathrm{~g}$ \\
\hline Control & 0 & 0 & $2.87 \pm 0.03 \mathrm{e}$ & $1.02 \pm 0.16 \mathrm{~g}$ & $19.85 \pm 0.02 \mathrm{~h}$ \\
\hline
\end{tabular}

In each column, values followed by the same letter are not significantly different as determined by Tukey's mean comparison test $(p \leq 0.05 ; n=4)$. The statistics were performed separately for the data in each column (means of four replicates, \pm standard error).

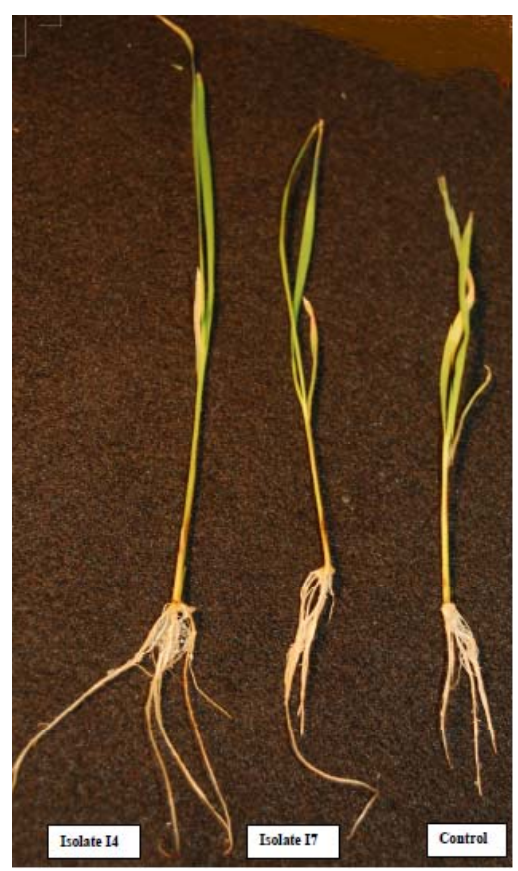

Figure 2. Increase in rice root hair number and length by IAA producing endophytes (I4 and I7) compared to uninoculated control under In vitro conditions. 


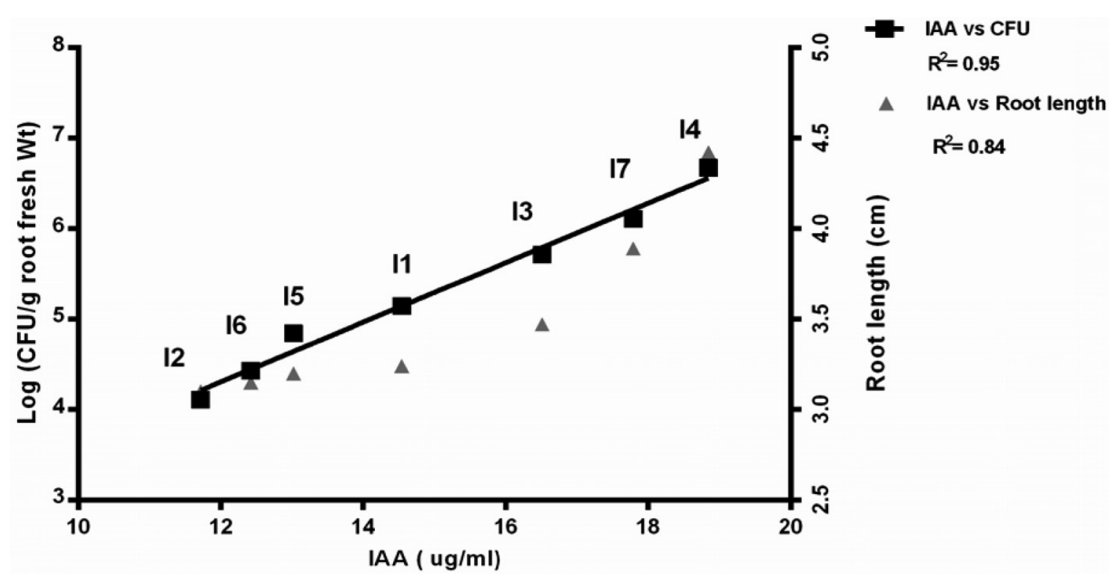

Figure 3. Correlation between IAA producing isolates with root length and the size of population by seven endophytic isolates reisolated from rice seedlings 20 days after inoculation under gnotobiotic conditions.

\section{Discussion}

Bacterial endophytes can be isolated from surfacedisinfected plant tissue or extracted from internal plant tissue (Hong Lia et al., 2008). To determine whether bacteria isolated from within canola plant tissue can have rice plant growth-promotion potential, colonize rice roots, and survive under flooded conditions, seeds of two rice cultivars were inoculated with individual bacterial isolates or mixtures of bacteria. They were isolated after surface sterilization of living roots. The colonization and growth promoting effects of seven IAA producing endophytic strains were compared in inoculated rice plantlets as single-strain inoculants. We found IAA producing isolates that not only significantly improved rice plant growth but also significantly increased the rate of colonization, when used for colonization assay. These results indicated that the endophytes had potential for promoting rice plant growth, but their real effect on plants was unclear. Since bacterial colonies that appear frequently and look morphologically different are randomly selected for further study by most researchers, they may miss the best isolates during screening; this study focused on a suitable screening for selecting the best isolates with high colonization and PGP potential. We inoculated rice plant with both endophytic isolates and rhizosphere isolates isolated from the canola roots. Because bacterial populations already resident within the host plant may well influence and be influenced by rhizosphere bacteria (Pajand and Paul, 2000). One of our aims of inoculating rice plants with the isolates obtained from canola was to examine their invasiveness and persistence. Out of 150 isolates inoculated on two rice cultivars, 22 bacterial endophytic isolates were reisolated, of which seven endophytes were used for further analysis and inoculated on Khazar cultivar (a bred variety). Screening the isolates was conducted based on both the rate of colonization and PGP traits, since the ability to colonize roots is a necessary condition for a rhizobacteria to be considered a true PGPR (Silva et al., 2003). Since aseptic technique was used throughout and the surface-sterilization procedure was considered effective, we may verify that the same bacteria inoculated to sterile rice seedlings could be re-isolated from these seedlings (to fulfill Koch's postulate), and examine their endophytic competence (infection and persistence characteristics). Seven 
strains had colonized the plants at levels ranging from 4.11 to $6.67 \log 10 \mathrm{CFU} \mathrm{g}^{-1}$ (fresh weight) at 20 days post inoculation. The number of CFU of these bacteria in roots fell in the range of endophytic bacteria (Wang et al., 2006). Interestingly, the endophytic isolates developed higher culturable endophytic populations in roots of Hashemi cultivar than in those of Khazar cultivar (Table 1). Thus, the degree to which endophytic isolates establish endophytic populations within rice cultivars among different cultivars (Yanni et al., 1997) and the extent of colonization was higher in roots in presence of $\mathrm{N}$; compared to roots in absence of $\mathrm{N}$ (Table 1). Nitrogen alters the physiological state of the plant, and this subsequently affects its association with the bacterial population (Reis et al., 2000). These results also show that rice represents a highly dynamic microenvironment for IAA producing isolates (Prakamhang et al., 2009). We have demonstrated that nitrogen fertilization was not a limiting factor for the recovery of the strains from internal plant tissues. However, Depending on its concentration, nitrogen can limit the bacterial invasion process (Mattos et al., 2008). Among all PGP traits evaluated in this study, IAA production, siderophore production and ACC deaminase appeared to be the most promising PGP traits in endophytic isolates respectively. The observations that the frequency of ACC deaminase, siderophore and IAA-producing bacteria is higher in the roots of canola plants suggests that the plant selects for endophytic bacteria with those traits or that these bacteria harbor other traits that allow them to more effectively reach and establish themselves in the inner plant tissue (Mendes et al., 2007). These results are similar to results of our previous study performed on berseem clover (Etesami et al., 2013; Etesami et al., 2014). IAA contributes to plant growth and development by increasing root growth and root length and has also been associated with proliferation and elongation of root hairs (Weyens et al., 2009). The capacity to synthesize IAA is widespread among soil and plant-associated bacteria (Glick, 2013). Due to the role of ACC deaminase in decreasing stress ethylene under flooding conditions (Glick, 2013) like our study, it is suggested that, rice seedlings may act as filters for ACC deaminase producing isolates too. In this study, the higher colonization levels of isolates I4 and I7 than other IAA producing isolates may be attributed to the production of ACC deaminase (Tables $1 \& 3$ ). The plant growth promoting effect is brought about by causing root elongation and proliferation that leads to enhanced water and mineral uptake by the host plant. Isolate I4 produced the highest amount of IAA with added tryptophan $\left(100 \mu \mathrm{g} \mathrm{ml}^{-1}\right)$. In our study, we found that IAA production is a conclusive characteristic, found in $100 \%$ of our recovered isolates. The positive effect of IAA depends on the amount of IAA produced by the bacterium, since an IAA over production is considered deleterious to plants (Ahmad et al., 2008). However, in this study, no clearly deleterious isolate was detected. None of the isolates were found to be deleterious to the rice plants. Findings of this study clearly demonstrated the presence of one or more than one types of PGP characters in majority of the isolates (Figure 1). However, among all PGP traits of the bacteria, the frequency of IAA-producers was found much higher than other PGP traits. Our findings are consistent with earlier reports where similar trend was reported in different bacteria (Ahmad et al., 2008; Mattos et al., 2008, Etesami et al., 2014). Since the initial step of bacteria invasion in plant root consists of the attachment of bacteria onto epidermal cells of the root surface, where root hair zone represent one of the major sites of primary colonization, mainly on the basal region of emerging hairs, it is possible that IAA producing isolates by increased root system can colonize plant roots better than other strains (Kuklinsky-Sobral et al., 2004; Mendes et al., 2007). The mechanism by which the isolates enhanced rice seedlings growth possibly could be its PGP attributes (phosphate solubilization, IAA, ACC deaminase and siderophore production), but in Hoagland' growth medium used in this study, Fe, $\mathrm{P}$ and $\mathrm{NH}_{4}^{+}$existed in soluble form. Therefore, IAA production may be the only mechanism of rice seedlings growth. Observation on root colonization in this study showed that also there was a correlation between IAA production and plant colonization (Figure 3). 


\section{Conclusions}

In summary, the results reported here show the isolates with IAA production can endophytically colonize rice plants. Moreover, the isolates confer beneficial effects on the growth of rice plants, possibly associated to IAA production which increases the rice plant development. The data obtained led us to conclude that the root colonization bioassay described here works well and is a reliable and efficient tool for helping in selection of endophytic isolates with good PGPR potential. It is concluded that the presence of IAA production ability could be a useful tool for screening effective endophytic bacteria to promote seedlings growth of rice under controlled conditions before testing their effectiveness under natural environment. Further field studies must be conducted to analyze the real potential of endophytic bacteria in field conditions. Our findings are based on laboratory cultivation, which may not reproduce exactly the conditions of natural environment, but may indeed help early rapid screening of the competent bacteria concerning high colonization and plant growth promoting ability, which can save time and expenses. In addition, this can be a good topic for more study to understand microbe-plant interactions. Therefore, proper screening of rice growth promoting bacteria can be useful for future agricultural applications, providing higher production yields, reduced input costs and negative environmental impact due to the use of nitrogen fertilizers.

\section{Acknowledgements}

We wish to thank the Head of the Soil Science Department, the Vice Chanceller for Research at University of Tehran, and Iran National Science Foundation (INSF) for providing the necessary facilities and founding for this study.

\section{References}

Ahmad, F., Ahmad, I., Khan, M.S. 2008. Screening of free-living rhizospheric bacteria for their multiple plant growth promoting activities. Microbiol. Res. 163, 173-181.

Antoun , H., Beauchamp, J., Goussard, N., Chabot, R., Lalande, R. 1998. Potential of Rhizobium and Bradyrhizobium species as plant growthpromoting rhizobacteria on non-legumes: Effect on radishes (Raphanus sativus L.). Plant. Soil. 204, 57-67.

Bhattacharyya, P.N., Jha, D.K. 2012. Plant growthpromoting rhizobacteria (PGPR): emergence in agriculture. World. J. Microbiol. Biotechnol. 28 (4), 1327-1350.

Etesami, H., Mirsyed Hosseini, H., Alikhani, H.A. 2013. Rapid screening of berseem clover (Trifolium alexandrinum) endophytic bacteria for rice plant seedlings growth-promoting agents. ISRN Soil. Sci.1-9.

Etesami, H., Mirsyed Hosseini, H., Alikhani, H.A., Mohammadi, L. 2014. Bacterial biosynthesis of 1-Aminocyclopropane-1-Carboxylate (ACC) deaminase and Indole-3-Acetic Acid (IAA) as endophytic preferential selection traits by rice plant seedlings. J. Plant. Growth. Regul. 1-17.

Glick, B.R. 2013. Bacteria with ACC deaminase can promote plant growthand help to feed the world. Microbiol. Res. 169 , 30-3915.

Hong Lia, J., Wang, E.T., Chena, W.F., Chen, W.X. 2008. Genetic diversity and potential for promotion of plant growth detected in nodule endophytic bacteria of soybean grown in Heilongjiang province of China. Soil. Biol. Biochem. 40, 238-246.

Kevin, V. J. 2003. Plant growth promoting rhizobacteria as biofertilizers. Plant Soil. 255, 571-586. 
Kuklinsky-Sobral, J., Araujo, W.L., Mendes, R., Geraldi, I.O., Pizzirani-Kleiner, A.A., Azevedo, J.L. 2004. Isolation and characterization of soybean-associated bacteria and their potential for plant growth promotion. Environ. Microbiol. 6, 1244-1251.

Lorck, H. 1948. Production of hydrocyanic acid by bacteria. Physiol. Plant. 1, 142-146.

Mattos, K.A., Pádua, V.L.M., Romeiro, A., Hallack, L.F., Neves, B.C., Ulissesi, T.M.U., Barros, C.F., Todeschini, A.R., Previat, J.O., Mendon, L., Previato, A. 2008. Endophytic colonization of rice (Oryza sativa L.) by the diazotrophic bacterium Burkholderia kururiensis and its ability to enhance plant growth. Anais da Academia Brasileira de Ciências. 80, 477-493.

Mendes, R., Pizzirani-Kleiner, A.A., Araujo, W.L., Raaijmakers, J.M. 2007. Diversity of cultivated endophytic bacteria from sugarcane: genetic and biochemical characterization of Burkholderia cepacia complex isolates. Appl. and Enviromen. Microbiol. 7259-7267.

Pajand, N., Paul, A.J. 2000. Endophytic bacteria induce growth promotion and wilt disease suppression in oilseed rape and tomato. Biol. Control. 18, 208215.

Patten, C., Glick, B. 2002. Role of Pseudomonas putida indoleacetic acid in development of the host plant root system. Appl. Environ. Microb. 68, 3795-3801.

Penrose, D.M., Glick, B.R. 2003. Methods for isolating and characterizing ACC deaminasecontaining plant growth promoting rhizobacteria. Physiol. Plant. 118,10-15.

Pikovskaya, R.I. 1948. Mobilization of phosphorus in soil connection with the vital activity of some microbial species. Microbiologiya. 17, 362-370.
Prakamhang, J., Minamisawa, K., Teamtaisong, K., Boonkerd, N., Teaumroong, N. 2009. The communities of endophytic diazotrophic bacteria in cultivated rice (Oryza sativa L.). Appl. Soil. Ecol. 142, 141-149.

Reis, V.M., Baldani, J.I., Baldani, V.L.D., Dobereiner, J. 2000. Biological dinitrogen fixation in Gramineae and palm trees. Crit. Rev. Plant. Sci. 19, 227-247.

Ryan, R.P., Germaine, K., Franks, A., Ryan, D.J., Dowling, D.N., 2008. Bacterial endophytes: recent developments and applications. FEMS Microbiol. Lett. 278, 1-9.

Schwyn, B., Neilands, J. 1987. Universal chemical assays for the detection and determination of siderophores. Anal. Biochem. 160, 47-56.

Silva, H.S.A., Silva, R.D., Mounteer, A. 2003. Development of a root colonization bioassay for rapid screening of rhizobacteria for potential biocontrol agents. J. Phytopathol. 151, 42-46.

Wang, L.L., Wang, E.T., Liu J, L.Y., Chen, W.X. 2006. Endophytic occupation of root nodules and roots of Melilotus dentatus by Agrobacterium tumefaciens. Microbial. Ecol. 52, 436-443.

Weyens, N., Vander Lelie, D., Taghavi, S., Newman, L., Vangronsveld, J. 2009. Exploiting plant-microbe partnerships to improve biomass production and remediation,. Trend. Biotech. 27, 591-598.

Yanni, Y.G., Rizk, R.Y., Corich, V., Squartini, A., Ninke, K., Philip-Hollingsworth, S., Orgambide, G., deBruijn, F., Stoltzfus, J., Buckley, D., Schmidt, T.M., Mateos, P. F., Ladha, J. K., Dazzo, F.B. 1997. Natural endophytic association between Rhizobium leguminosarum bv. trifolii and rice roots and assessment of its potential to promote rice growth. Plant. Soil. 194, 99-114. 